\title{
Activated androgen receptor accelerates angiogenesis in cutaneous neurofibroma by regulating VEGFA transcription
}

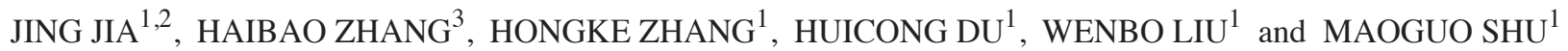 \\ ${ }^{1}$ Department of Plastic, Cosmetic and Maxillofacial Surgery, The First Affiliated Hospital of Xi'an Jiaotong University; \\ ${ }^{2}$ The School of Electronic and Information Engineering, and \\ ${ }^{3}$ Key Laboratory for Tumor Precision Medicine of Shaanxi Province, Xi'an Jiaotong University, \\ Xi'an, Shaanxi 710061, P.R. China
}

Received November 23, 2018; Accepted April 24, 2019

DOI: $10.3892 /$ ijo.2019.4797

\begin{abstract}
Accumulating evidence has demonstrated the significant progression of cutaneous neurofibroma (cNF) without necrosis during puberty. However, the molecular events involved in this process remain unclear. The alteration of the steroid hormone levels during puberty has led to the investigation of the expression levels of the androgen receptor (AR). A positive correlation between AR expression and microvessel density has been reported in human cNF tissues in combination with enhanced endothelial cell tube formation in vitro. In addition, activated AR signaling can promote neurofibroma cell growth in vivo and in vitro and tube formation in vitro. In the present study, AR was shown to bind directly to the promoter of vascular endothelial growth factor A (VEGFA), a key factor involved in angiogenesis, and to sequentially induce its expression. Furthermore, the AR inhibitor, MDV3100, downregulated VEGFA expression and abolished endothelial cell recruitment and tube formation. Taken collectively, the findings of this study revealed that AR signaling enhanced tumor growth and angiogenesis in CNF by regulating VEGFA transcription. However, whether AR can be regarded a therapeutic target for $\mathrm{cNF}$ requires further investigation.
\end{abstract}

\section{Introduction}

Neurofibromatosis type 1 (NF1) is an autosomal-dominant inherited tumor susceptibility syndrome with an incidence of approximately 1 per 3,000-4,000 individuals worldwide (1). From a clinical perspective, patients with NF1 present with café-au-lait macules, Lisch nodules, gliomas of the optic

Correspondence to: Dr Maoguo Shu, Department of Plastic, Cosmetic and Maxillofacial Surgery, The First Affiliated Hospital of Xi'an Jiaotong University, 277 Yanta West Road, Xi'an, Shaanxi 710061, P.R. China

E-mail: maoguo_shu@126.com

Key words: cutaneous neurofibroma, androgen receptor signaling, angiogenesis, vascular endothelial growth factor A tract, specific osseous lesions and neurofibromas (2). As the main manifestation of patients with NF1, neurofibromas are classified based on the anatomical region, such as cutaneous, subdermal, plexiform and intraneural neurofibromas. Plexiform neurofibromas indicate a malignant tendency, whereas cutaneous neurofibromas (cNFs) are considered the hallmark of NF1 (2). These tumors are undetectable at birth and appear during adolescence (2). Although malignant progression is a rare event in $\mathrm{cNF}$, the psychosocial management of this disease should not be ignored. Surgery and laser therapy exhibit limited effectiveness in the treatment of cNF. However, they are the only type of treatment for large-sized cNF tumors. The lack of standard therapeutic modalities has led to the continuous search for novel treatment options.

cNFs usually appear at puberty and plexiform neurofibromas are capable of aggressive growth during puberty $(3,4)$. The contributions from the genetic background of each patient (gene mutations) and from the environmental conditions (trauma and altered hormone levels) may act as 'triggers' for tumorigenesis, enlargement, or malignant progression (5). Steroid hormones contribute to the development of a number of tumors, such as breast, and prostate cancer, renal cell carcinoma and benign meningioma. Nevertheless, a limited number of studies have been performed to investigate the role of steroid hormones in neurofibromas. Previous studies have examined the expression levels of estrogen receptor (ER) and progesterone receptor (PR) on cultured Schwann cells (6-8). The proliferative response to estradiol and progesterone was further detected in these cells (6-8). Moreover, no difference was noted in the progression of neurofibromas during puberty between the two sexes. Rare cross-reactivity or binding to non-native receptors has been noted following steroid binding (9). Considering the elevated androgen levels in adolescent male patients with NF1, particular attention has been paid on the function of the androgen receptor (AR) as regards the progression of neurofibroma.

Neurofibroma is a highly vascularized tumor (10) that can increase substantially in size without avascular necrosis. Previous studieshave shown that the activation of platelet-derived growth factor receptor (PDGFR) and vascular endothelial growth factor receptor (VEGFR) can occur in the neurofibroma microenvironment $(11,12)$. Furthermore, the application of 
specific inhibitors for VEGFR and PDGFR has been shown to reduce growth and induce regression of neurofibroma in a mouse model (13). The malignant transformation and progression of several tumors is linked to angiogenesis and is dependent on the induction of this process (14-16). The 'angiogenic switch' is usually triggered following two possible processes: The reduction in the angiogenesis inhibitors and/or the activation of the angiogenesis inducers (17). Among the inducers, VEGF plays a pivotal role in tumor angiogenesis, due to the prominent, although not exclusive, expression of VEGFR on endothelial cells. In addition, the ligand, vascular endothelial growth factor (VEGF), is usually secreted by tumor cells and the stroma (18). Moreover, AR signaling plays critical roles in mediating angiogenesis in various tumors.

In the present study, we demonstrated that activated AR signaling promotes neurofibroma angiogenesis by modulating VEGFA expression and secretion. Specific inhibitors targeting AR signaling may thus suppress cNF progression and improve its treatment.

\section{Materials and methods}

Chemicals and reagents. MDV3100 (enzalutamide) was purchased from Selleck Chemicals and dihydrotestosterone (DHT) from Sigma-Aldrich. X-treme GENE HP DNA transfection reagent was obtained from Roche and the simpleChIP ${ }^{\circledR}$ enzymatic chromatin IP kit (Magnetic Beads) from Cell Signaling Technology, Inc. All the reagents were stored and used according to the protocol provided by the manufacturer. The primary antibodies for neurofibromin (ab17963) and VEGFA (ab46154) were purchased from Abcam. The primary antibody for AR (\#5153) was purchased from Cell Signaling Technology, Inc.

Cell culture and RNA interference. Murine SW10 Schwann cells and human skin fibroblasts were propagated in DMEM/F12 with $10 \%$ fetal bovine serum (FBS). The cells were maintained in a humid atmosphere with $5 \% \mathrm{CO}_{2}$ at $37^{\circ} \mathrm{C}$. Recombinant replication-defective lentiviruses harboring Nfl-specific short hairpin RNA (shRNA) or control shRNA were employed to transfect the cells, which were then named shNf1 or shNC cells, respectively. The efficiency of shRNA transfection was detected by western blot analysis. The siRNAs targeting AR were purchased from RiboBio. The cells were infected by lentiviruses at a confluence of $70-80 \%$ or transfected with siRNA using X-treme GENE siRNA Transfection Reagent (Roche) at a confluence of 30-50\%.

Patients and tissue samples. Paraffin-embedded tissues from 29 patients with NF1 were collected from the first Affiliated Hospital of Xi'an Jiaotong University and used for the immunohistochemical (IHC) analysis of AR, CD31 and VEGFA expression. The tissue procurement protocol was approved by the Institutional Review Board and informed consent was provided from each patient. The sections with a thickness of $5 \mu \mathrm{m}$ were derived from all the paraffin-embedded tissues and were accordingly prepared. The staining for AR (1:200), VEGFA (1:200) and CD31 (1:150) was performed using the DAKO Autostainer Plus system. One pathologist analyzed the sections under a high-power field (x400 magnification) in a double-blind protocol setup. Microvessels were defined as CD $31^{+}$endothelial cells or a cell cluster detached from any microvessel structures. The average number of microvessels from 10 random fields was defined as the microvessel density (MVD). The AR staining score was calculated by both intensity and percentage. The tendency score was estimated as follows: 0, 1, 2 and 3 indicated no staining, weak positive staining, moderate positive staining and strong positive staining, respectively. The percentage score was estimated as follows: $0,0 \% ; 1, \leq 25 \% ; 2,25-50 \%$; $3,50-75 \%$; and $4, \geq 75 \%$. The total score was calculated by the multiplication of the intensity score with the percentage score. The clinicopathological characteristics of the patients are presented in Table I.

RNA extraction and reverse transcription-quantitative $P C R$ analysis $(R T-q P C R)$. A total RNA extraction kit (Fastagen Biotech) was used to extract the total RNA, which was subsequently subjected to reverse transcription by SuperScript III Transcriptase (Thermo Fisher Scientific). qPCR was performed using the Bio-Rad CFX96 system with SYBR-Green for analysis of the mRNA levels of each specific gene. Human GAPDH cDNA was used as the internal control. The primer sequences are listed in Table SI. The PCR thermocycling conditions were as follows: Step 1: $95^{\circ} \mathrm{C}, 30 \mathrm{sec}, 1 \mathrm{x}$; step 2: $95^{\circ} \mathrm{C}, 0 \mathrm{sec}$, and $60^{\circ} \mathrm{C}$, $30 \mathrm{sec}, 39 \mathrm{x}$; step 3: $4^{\circ} \mathrm{C},+\infty, 1 \mathrm{x}$.

Western blot analysis. RIPA lysis buffer containing protease inhibitor was used for total protein extraction. The Bradford assay was used to detect the protein concentration. Briefly, $12 \%$ SDS-polyacrylamide gels were used to separate $30 \mu \mathrm{g}$ of protein prior to blotting onto the nitrocellulose filter membranes. Non-fat-milk (5\%) in Tris-buffered saline and Tween-20 were used to block the non-specific bindings sites of the membranes. The membranes were incubated with specific primary antibodies overnight at $4^{\circ} \mathrm{C}$ and the following day with secondary antibodies for $1 \mathrm{~h}$ at room temperature. Molecular Imager ChemiDoc XRS System (Bio-Rad Laboratories, Inc.) was used to visualize the protein bands. Immunoblotting of GAPDH was used as the internal control. The primary antibodies for neurofibromin (ab17963, 1:1,500) and VEGFA (ab46154, 1:1,500) were purchased from Abcam. Primary antibody for AR (\#5153, 1:1,000) and horseradish peroxidase-conjugated secondary antibodies (\#7074 for anti-rabbit IgG and \#7076 for anti-mouse IgG, 1:200) were purchased from Cell Signaling Technology, Inc.

Conditioned medium collection and ELISA. A total of 5x10 shNf1-SW10 cells or shNf1 fibroblasts were seeded in a 60 -mm culture dish. Following $24 \mathrm{~h}$ of incubation, the cells were washed with serum-free medium (SFM) 3 times, and an additional $5 \mathrm{ml}$ of SFM were added. The cells were then cultured for an additional $24 \mathrm{~h}$ at $37^{\circ} \mathrm{C}$. The supernatants were centrifuged $(1,000 \mathrm{x} \mathrm{g}, 5 \mathrm{~min})$ to remove the cell debris and the conditioned medium $(\mathrm{CM})$ was stored at $-80^{\circ} \mathrm{C}$. The RayBio ${ }^{\circledR}$ Human VEGF ELISA kit (RayBiotech Inc.) was used to examine the concentration of VEGF in CM. The VEGF concentration was modified by the addition of neutralizing VEGF antibody (MAB293) or the addition of recombinant human VEGF (AF-293-NA) (both from R\&D Systems). 
Table I. Clinicopathologic characteristics of the patients with neurofibromatosis type 1 .

\begin{tabular}{lr}
\hline Characteristic & No. $(\%)$ \\
\hline Age (years) & \\
$\leq 20$ & $14(48.3)$ \\
$>20, \leq 40$ & $10(34.5)$ \\
$>40$ & $5(17.2)$ \\
Sex & \\
Female & 0 \\
Male & 29 \\
\hline
\end{tabular}

3-(4,5-Dimethylthiazol-2-yl)-2,5-diphenyltetrazolium bromide (MTT) assay. Cell viability and growth rate were analyzed by

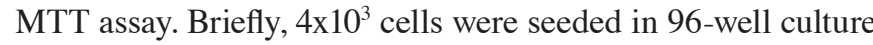
plates. After $24 \mathrm{~h}$, the cells were treated with DHT (5 nM) or DMSO for the indicated time periods $(0,24,48$ and $72 \mathrm{~h})$. The cells were then washed and incubated with MTT solution (M2128; Sigma-Aldrich) $(0.5 \mathrm{mg} / \mathrm{ml})$ at $37^{\circ} \mathrm{C}$. Following $4 \mathrm{~h}$ of incubation, the medium was carefully removed and $150 \mu 1$ of DMSO was used to solubilize the formazan crystals. The absorbance of each well was detected by a microplate automatic reader (Bio-Tek Instruments, Inc.) at $490 \mathrm{~nm}$.

Androgen-AR mediated Schwann cell growth in vivo. A total of 12 4-week-old nude mice were randomly allocated to 2 groups with random digits. All mice were injected with $2 \times 10^{6}$ shNf1-SW10 cells subcutaneously. One week later, the mice in the 2 groups were treated daily with $100 \mu \mathrm{l}$ of saline and with $0.6 \mathrm{mg} / \mathrm{kg}$ of DHT, respectively. The body weight was measured every 3 days. Following 4 weeks of xenograft tumor growth, the mice were sacrificed and the tumors were excised surgically and measured. A solution with $4 \%$ paraformaldehyde was used to fix the tumors. The samples were embedded in paraffin, and IHC staining of VEGFA expression was performed. The animal experiments were approved by the Institutional Review Board of the First Affiliated Hospital of Xi'an Jiaotong University.

Colony formation assay. A total of 1,000 shNf1-SW10 cells or shNf1 fibroblasts were seeded into 1 well of a 6-well plate. The cells were treated with DHT $(5 \mathrm{nM})$ or saline for 2 weeks. Subsequently, the cells were washed, fixed with $4 \%$ paraformaldehyde and stained with $0.1 \%$ crystal violet (C6158; Sigma-Aldrich) solutions for $15 \mathrm{~min}$ at room temperature. The cells were then washed with PBS 3 times at room temperature. Visible cell colonies in each well were counted and the average colony number of each treatment was calculated.

Tube formation assay. The human umbilical vascular endothelial cell (HUVEC) cell line was purchased from the American Type Culture Collection (ATCC). SFM or SFM added with CM (1:1) were prepared for HUVEC $\left(1 \times 10^{5}\right)$ culture. A 24-well plate with Matrigel-coated wells was used for the tube formation assay. Imaging was conducted using an optical microscope (IX50-S8F2; Olympus) at the 6-h time period. A tube was identified as 2 branching points that were perfectly connected.
Cell cycle analysis. The cells were passaged at a confluence of 60-80\% with Trypsin/EDTA. Subsequently, the cells were washed with cold PBS resuspended in ice-cold $70 \%$ ethanol and stored for $>24 \mathrm{~h}$ at $-20^{\circ} \mathrm{C}$. On the day of the analysis, the ethanol was removed and the cells were washed 2 times with cold PBS. RNAse A $(0.5 \mu \mathrm{g} / \mathrm{ml})$ and propidium iodide (50 $\mu \mathrm{g} / \mathrm{ml})$ were added to the cells that were incubated at room temperature for $30 \mathrm{~min}$ in the dark prior to flow cytometric analysis (BD FACSCalibur ${ }^{\mathrm{TM}}$ Flow Cytometer; BD Biosciences).

HUVEC migration assay. Transwell migration analysis was conducted by $8-\mu \mathrm{m}$-pore Transwell inserts (Millipore Corp.). HUVECs $\left(3 \times 10^{5}\right.$ cells $\left./ \mathrm{ml}\right)$ were mixed with $300 \mu \mathrm{l}$ of SFM and subsequently seeded into the upper chamber of the Transwell. In the lower chamber, $1 \mathrm{ml}$ of CM or neurofibroma cells treated with reagents was added. Following $16 \mathrm{~h}$ of culture, the cells that migrated to the lower surface of the inserts were fixed with $4 \%$ paraformaldehyde and stained using $0.1 \%$ crystal violet for $15 \mathrm{~min}$ at room temperature. The visible cells were counted in 5 random fields (x200 magnification) for each insert with an optical microscope (IX50-S8F2; Olympus).

Dual luciferase activity assay. The promoter region of VEGFA $(-1618$ to +100$)$ was amplified and inserted into the pGL3-basic plasmids (GenePharma), denoted as pGL3-VEGFA. Nf1-ablated SW10 cells and fibroblasts were transfected with pGL3-basic or pGL3-VEGFA by X-tremeGENE HP DNA transfection reagent (Roche). A control sample was prepared by the addition of the DNA transfection reagent without any plasmids (pGL3-control). A dual luciferase assay kit (Promega) was used for the luciferase assay following the instructions of the manufacturer. The luciferase activity of each well was normalized by comparison with Renilla luciferase activity. The data from 3 wells were collected and the average value was used for analysis of luciferase activity of each sample. The primers used for PCR amplification were the following: forward (5'-ATTCCCATTCTCAGTCCATG-3') and reverse (5'-CTGACCGGTCCACCTAACCG-3').

Chromatin immunoprecipitation assay. The SimpleChIP ${ }^{\circledR}$ enzymatic chromatin IP kit was used for ChIP assay in Nf1-ablated SW10 cells and fibroblasts following the indicated protocol. The precipitation of the protein/DNA complex was achieved by antibodies against the AR (\#5153, 1:50; Cell Signaling Technology, Inc.) or against normal rabbit $\operatorname{Ig} G$ (from the kit). The DNA of interest was detected with genetic region-specific primers (Table SII) and amplified by PCR.

Oligonucleotides pull-down assay. Biotin was added to the oligonucleotides of the specific sets of the VEGFA promoter (biotin-5'-CTTCCCCTGCCCCCTTCAATATTCCTAGCAAA GAGGGAACGGCTCT-3', synthesized by GENEWIZ). The lysis buffer contained $\mathrm{NaCl}(150 \mathrm{mM})$, Tris $\mathrm{HCl}(50 \mathrm{mM}$, pH 7.4), EDTA (1 mM) and Triton X-100 (1\%). Nfl-ablated SW10 cells and fibroblasts were treated with $10 \mathrm{ng} / \mathrm{ml}$ of DHT for the indicated time periods $(0,12,24$ and $36 \mathrm{~h})$. The cells were lysed in lysis buffer with protease and phosphatase inhibitors. Following centrifugation $\left(15,000 \mathrm{x} \mathrm{g}, 4^{\circ} \mathrm{C}, 15 \mathrm{~min}\right), 20 \mu \mathrm{l}$ of ImmunoPure streptavidin-agarose beads were added to each cell 
A

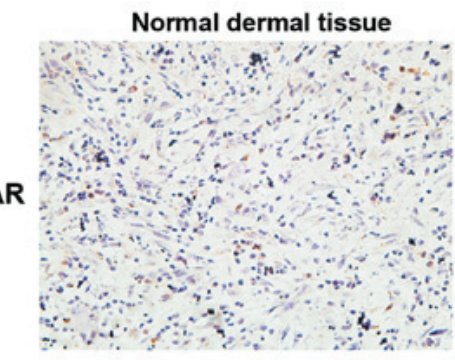

B

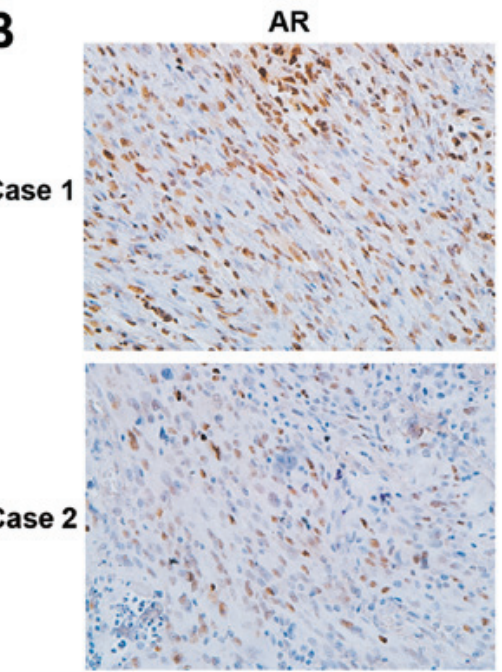

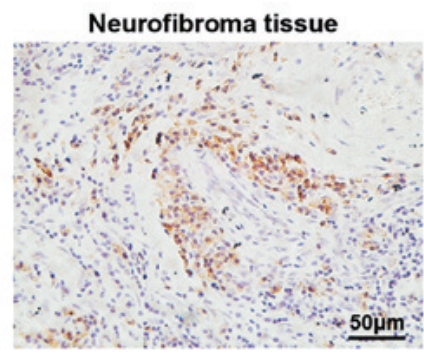

CD31

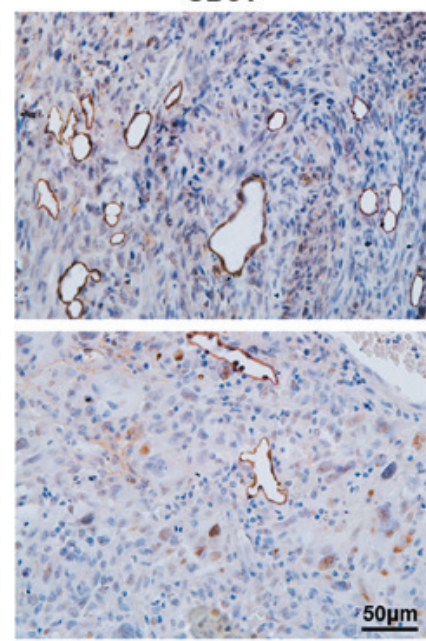

C

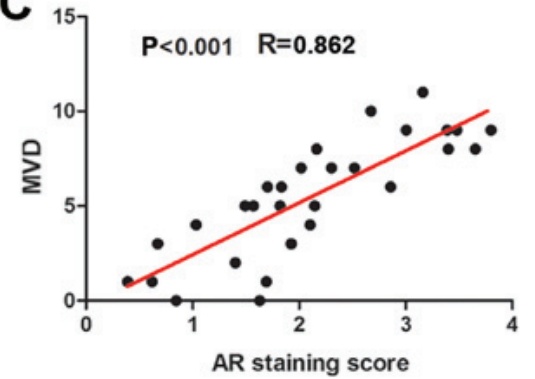

D

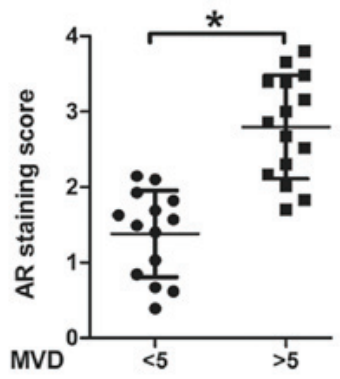

Figure 1. Increased androgen receptor (AR) expression in cNF correlates with microvessel density. A total of $29 \mathrm{cNF}$ tissues and 29 adjacent dermal tissues were used for immunohistochemical analysis with antibodies against AR and CD31. All sections were analyzed under the high-power field (x400 magnification) with a double-blind study design. One pathologist counted the number of the CD $31^{+}$endothelial cells or the number of the CD31 ${ }^{+}$cell cluster in each section. Microvessel density (MVD) was identified as the average number of vessels counted in 10 random fields. (A) Representative images of androgen receptor (AR) positive cells in cNF and adjacent normal tissues. (B) Representative images of 2 cNF samples with high AR density-high MVD and low AR density-low MVD. (C) Spearman's correlation analysis of the correlation between MVD and AR density. (D) MVD levels in cNF samples with different AR density. Low, AR density $<5, \mathrm{n}=14$ cases; High, AR density $>5, \mathrm{n}=5$ cases. ${ }^{*} \mathrm{P}<0.05$.

extract at $4^{\circ} \mathrm{C}$. Following $1 \mathrm{~h}$ of incubation at $4^{\circ} \mathrm{C}$, the bead-bound cell extracts were centrifuged at $5,000 \mathrm{x} \mathrm{g}$ for $1 \mathrm{~min}$ at $4^{\circ} \mathrm{C}$. The supernatant was collected and incubated with 100 pmol of biotinylated oligonucleotides at $4{ }^{\circ} \mathrm{C}$ for $24 \mathrm{~h}$. The immobilized streptavidin-agarose beads $(30 \mu \mathrm{l})$ were used to precipitate DNA-bound proteins at $4^{\circ} \mathrm{C}$. Following $1 \mathrm{~h}$ of incubation, centrifugation $\left(5,000 \times \mathrm{g}, 4^{\circ} \mathrm{C}, 1.5 \mathrm{~min}\right)$ was performed and the supernatant was carefully discarded. The precipitate was washed 3 times with lysis buffer prior to western blot analysis.

Statistical analysis. Statistical analyses were performed by GraphPad Prism (version 5.0; GraphPad Software, Inc.) software, and the Student's t-test was used for 2-group comparisons. For comparisons of $>2$ groups, we used one-way ANOVA and Fisher's Least Significant Difference test (LSD test) with statistical software SPSS for Windows 10.0. For the correlation analysis, we employed the Spearman's correlation test with SPSS. A P-value $<0.05(\mathrm{P}<0.05)$ was considered to indicate statistically significant differences.

\section{Results}

AR expression is positively associated with cNF angiogenesis. To explore the potential association of AR expression and $\mathrm{cNF}$ angiogenesis, we performed IHC assays with antibodies against AR and CD31 (marker of vascular endothelial cells) of $29 \mathrm{cNF}$ and 29 adjacent normal dermal tissues from male patients. The results revealed significantly elevated AR expression levels in cNF tissues compared with those noted in adjacent tissues (Fig. 1A). CD31 staining of the cNF tissues indicated an increased MVD (Fig. 1B) and an enhanced AR expression that was associated with MVD (Fig. 1D). Moreover, a positive linear correlation was noted between MVD and AR expression in the human $\mathrm{cNF}$ tissues $(\mathrm{r}=0.862, \mathrm{P}<0.001$, Fig. 1C). Taken collectively, the results indicated that AR expression was positively associated with angiogenesis in human $\mathrm{cNF}$ samples (Fig. 1).

Activated AR promotes neurofibroma the proliferation of shNf1-SW10 cells and shNf1 fibroblasts in vitro and in shNf1-SW10 xenografts in vivo. The loss-of-function mutation of the $N f 1$ gene is considered a major genetic change responsible for the development of the NF1 type disease. Therefore, we constructed $N f 1$ knockout $(\mathrm{k} / \mathrm{o})$ SW10 cells and $N f 1 \mathrm{k} / \mathrm{o}$ fibroblasts using lentivirus-delivered specific shRNA (Fig. 2A). To further identify the role of AR signaling in neurofibroma, we monitored the activation of the AR with DHT binding and examined the enhanced cellular proliferation by MTT assay (Fig. 2B). In addition, we performed s colony formation assay and noted an increased colony number in the aforementioned groups (Fig. 2C). Moreover, DHT treatment resulted in an increased number 

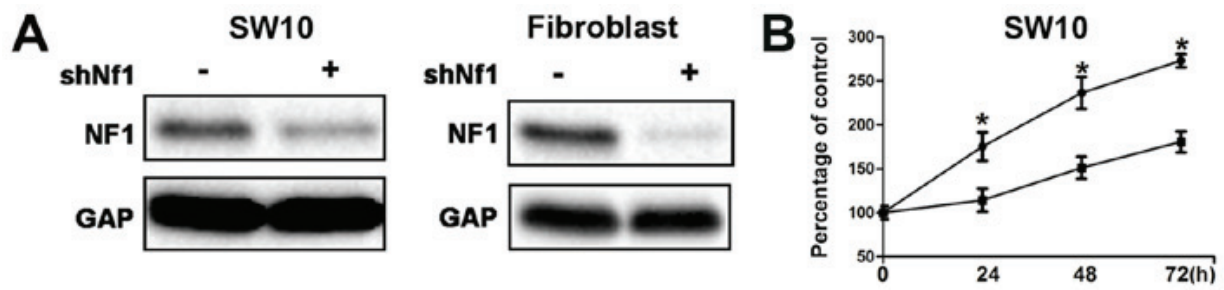

C

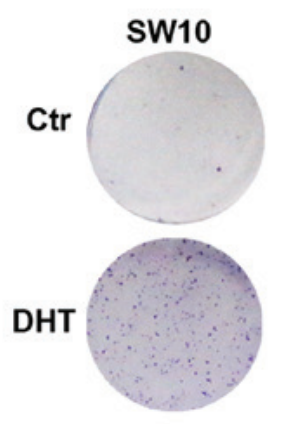

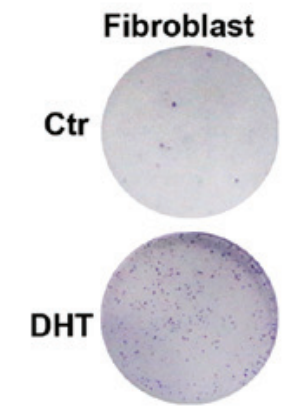
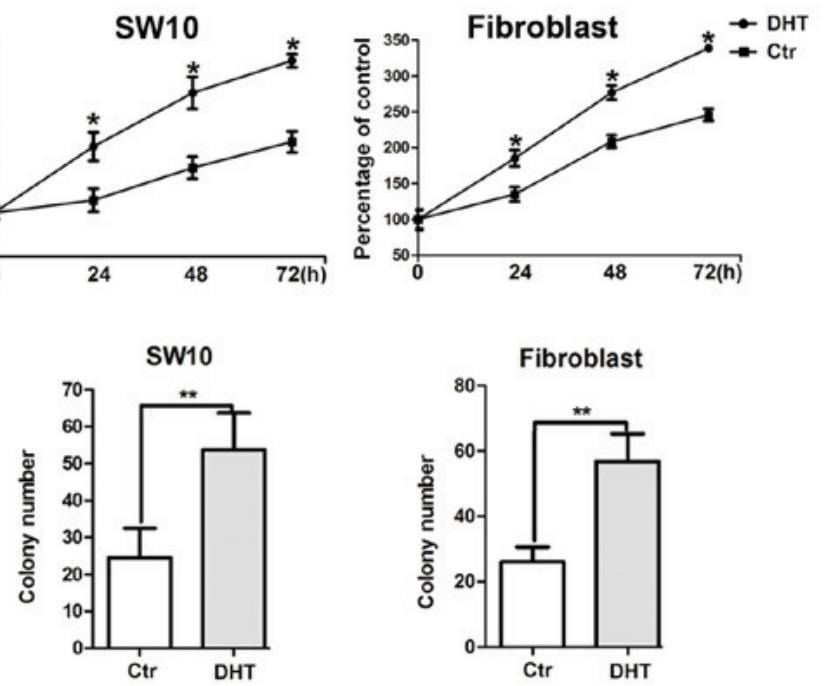

D

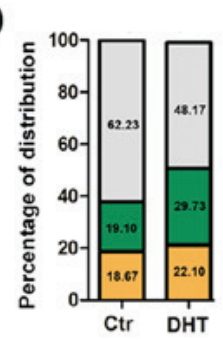

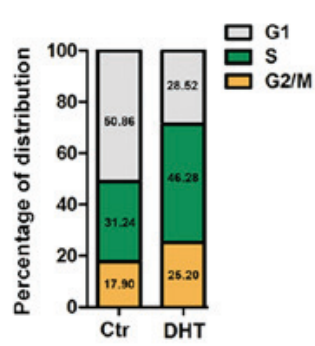

E

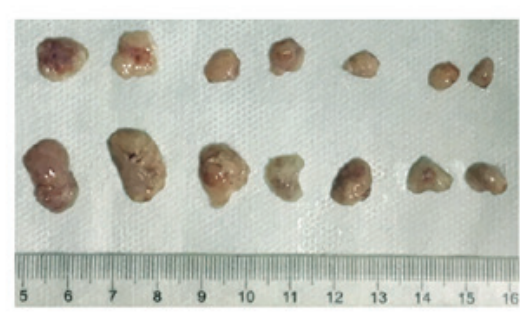

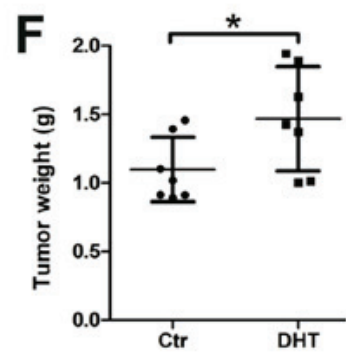

Figure 2. Lentiviral Nf1 knockdown suppresses the viability of neurofibroma cells in vitro and in vivo. (A) Lentiviruses containing negative control (NC) or Nf1 shRNAs were used to transfect SW10 and fibroblasts. Western blot analysis of neurofibromin expression in transfected cells with GAPDH as the internal control. (B) Growth rate of shNf1-cells treated with dihydrotestosterone (DHT) or DMSO, as determined by the MTT assay. (C) Colony-formation activities of shNf1-SW10 and shNf1-fibroblast clones with or without DHT-activated androgen receptor (AR), right: quantification of colony number. (D) Cell cycle analysis of the aforementioned cell clones. (E) Subcutaneous xenografts of shNf1-SW10 clones were harvested 3 weeks following DHT treatment. (F) Comparison of tumor weights with or without DHT treatment. ${ }^{*} \mathrm{P}<0.05$ and ${ }^{* *} \mathrm{P}<0.01$.

of cells entering the $\mathrm{S}$ phase, as demonstrated by flow cytometric assay (Fig. 2D).

Furthermore, the subcutaneous tumorigenesis potential of the shNf1-SW10 cells was significantly increased following DHT intraperitoneal injection. Following 4 weeks of xenograft growth, tumor weight was considerably higher in the DHT-treated nude mice compared with that noted in the control animals $(1.468 \pm 0.1434 \mathrm{mg}, \mathrm{n}=7 \mathrm{vs} .1 .098 \pm 0.08905 \mathrm{mg}$, $\mathrm{n}=7$ ) (Fig. 2E).

Taken collectively, the results demonstrated that active AR signaling promoted neurofibroma cell viability (Fig. 2), which is consistent with the clinical observations regarding the increased number and size of neurofibroma during puberty.

\section{AR signaling promotes the angiogenesis of neurofibroma. Since} AR expression was increased with MVD in human cNF tissues, we employed HUVEC recruitment assays to further confirm the effects of AR signaling on angiogenesis. Briefly, DHT- or saline-treated shNf1-SW10 cells and shNf1 fibroblasts were seeded to the lower chamber or $\mathrm{CM}$ from Nf1 ablated cNF cells with or without treatment with DHT were added to the lower chamber of the Transwell and the HUVECs were seeded in the upper chamber of the Transwell. Following incubation at $37^{\circ} \mathrm{C}$ for $16 \mathrm{~h}$, the CM from DHT-treated cells attracted additional HUVECs to the lower surface of the upper chamber compared with those of the control group (Fig. 3A and B, quantitative data). As regards the co-culture system, neurofibroma cells were seeded in the upper chamber and HUVECs were added to the lower chamber. We detected multiple viable cells in the HUVECs co-cultured with neurofibroma cells and in HUVECs treated with DHT (Fig. 3C). Moreover, the capillary tube formation on Matrigel was significantly higher in the DHT-treated shNf1-SW10 cells compared with that of the control cells (Fig. 3D).

On the whole, the results shown in Fig. 3 suggest that the activated AR signaling may modulate the paracrine function of neurofibroma cells and may alter the interaction of neurofibroma cells with HUVECs. These processes can promote angiogenesis.

$A R$ regulates VEGFA expression and mediates angiogenesis in neurofibroma. Since AR binds to DNA and promotes the transcription of target genes, we hypothesized that the activation of AR signaling may cause the release of angiogenic factors and promote angiogenesis in neurofibroma. Therefore, we performed RT-qPCR assay and detected the expression levels of angiogenic cytokines in shNf1-SW10 cells with or without DHT treatment. Statistical analysis indicated that VEGFA and IGF-1 were key players involved in angiogenesis of neurofibroma cells (Fig. 4A). Considering the predominant roles of VEGFA in tumor angiogenesis, we focused on the regulation of VEGFA by AR. The mRNA and protein 

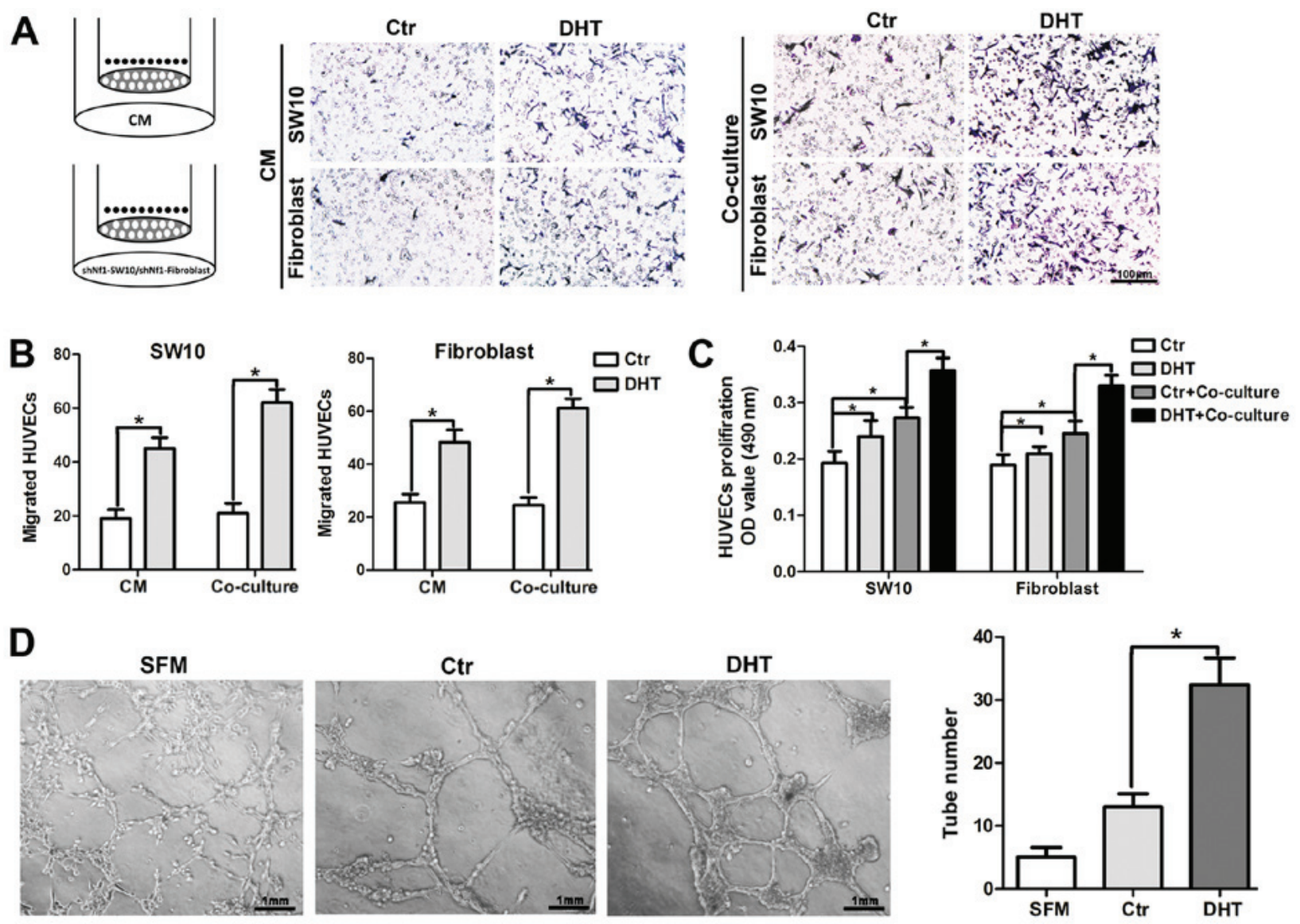

Figure 3. Androgen receptor (AR) promotes neurofibroma angiogenesis in vitro and in vivo. (A) The conditioned medium collected from $2 \times 10^{6} \mathrm{DHT}$-treated cNF cells was added to the lower chamber of the Transwell or DHT-treated cNF cells were seeded to the lower chamber. HUVECs were seeded in the upper chamber of the Transwell system and the number of recruited HUVEC were counted in 6 random fields (x200 magnification) (left panel, schematic for HUVEC recruitment assay; right panel, representative images). (B) Quantitative data of HUVEC recruitment. (C) HUVECs treated with DHT or cultured with shNf1-SW10 cells and/or shNf1 fibroblasts in the upper chamber for $48 \mathrm{~h}$ were used to evaluate cell viability. (D) DHT promoted tube formation of HUVECs. HUVECs diluted in serum free medium (SFM) with or without CM were seeded in the Matrigel-coated wells for $4 \mathrm{~h}$ of incubation. The tube was identified as 2 branching points that were perfectly connected. Representative images of tubes are presented and the tube number in each well was counted (right panel). ${ }^{*} \mathrm{P}<0.05$.

expression levels of $V E G F A$ were significantly increased following DHT treatment (Fig. 4B and C). In addition, the expression levels of VEGFA were monitored in DHT-treated tumors (Fig. 4D). The transfection of shNf1-SW10 cells and shNf1 fibroblasts with AR-specific siRNA effectively impaired AR expression and reduced VEGFA expression (Fig. 4E). Furthermore, ELISA was performed to detect the reduction in VEGFA secretion caused by siAR transfection and the increase in VEGFA expression following DHT treatment in the medium (Fig. 4F and G). The data indicated that the inhibition of the AR signaling could be considered a novel strategy to abolish HUVEC recruitment. Taken together, these data demonstrated that AR signaling regulated neurofibroma angiogenesis by promoting VEGFA expression.

AR enhanced VEGFA transcription by direct interaction with the VEGFA promoter. AR has been shown to bind to the promoters of target genes at the androgen receptor binding element (ARE). We found 7 putative AREs approximately $1,700 \mathrm{bp}$ from the transcription initiation site (Fig. 5A). Subsequently, we cloned the DNA fragment, which was inserted into the pGL3-basic luciferase reporter plasmid to construct the pGL3-VEGFA plasmid. The dual luciferase assay in shNf1-SW10 cells and shNf1 fibroblasts indicated that DHT significantly enhanced the activity of pGL3-VEGFA plasmids (Fig. 5B), which confirmed the increase in VEGFA mRNA levels in DHT-treated cells. Four primer pairs specific for amplifying different regions of the VEGFA promoter were employed in the ChIP assay. A total of 2 out of 4 regions maintained a higher binding affinity with the AR (Fig. 5C). To further clarify whether AR binds directly to the $-400 /-50$ region, which is close to the transcription initiation site of the VEGFA promoter, oligonucleotides with the same sequences were synthesized with biotin bound at the 5' terminus to pull-down the AR proteins. The cells that had been treated with DHT indicated the amplification of AR binding to the VEGFA promoter, which explained the upregulation in the expression of VEGFA following DHT treatment (Fig. 5D). Taken collectively, these data suggested that AR acted as a transcription factor bound directly to the VEGFA promoter that could initiate its transcription (Fig. 5).

Inhibition of AR signaling suppresses angiogenesis in neurofibroma. The activation of the AR signaling can increase VEGFA expression and secretion, by promoting neurofibroma angiogenesis. Therefore, we further explored the latent therapeutic action of AR targeting in neurofibroma. Enzalutamide or MDV3100 is an androgen receptor antagonist 

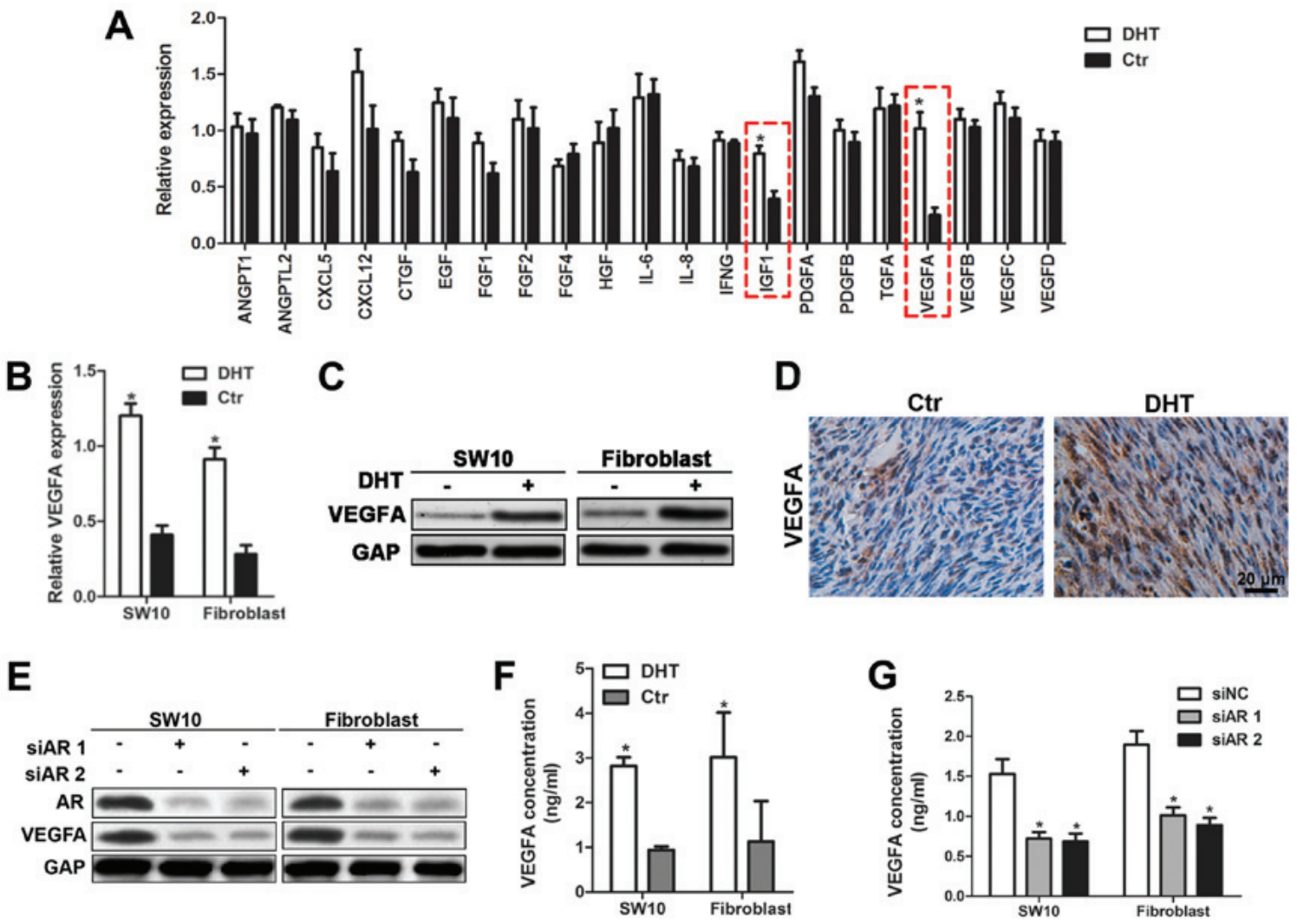

Figure 4. Androgen receptor (AR) modulates VEGFA expression in neurofibroma cells. (A) RT-qPCR was applied to examine the expression of angiogenic cytokines in shNf1-SW10 cells with or without DHT treatment. (B) DHT increased the expression levels of VEGFA in SW10 cells and in fibroblasts following Nf1 knockdown. (C) Western blot analysis was used to analyze VEGFA protein levels in DHT-treated cells. (D) Representative images of VEGF expression in a mouse model. (E) Specific siRNA targeting AR (siRNA 1 and 2 for AR) were used to knockdown AR in SW10 cells and in fibroblasts. The protein levels of AR and VEGFA were analyzed. (F and G) Conditioned medium (CM) from AR knockdown cells or DHT-treated cells was collected and the secreted VEGFA levels were determined by ELISA in the CM. " $\mathrm{P}<0.05$.

that was selected to reduce the activation of the AR signaling. MDV3100 reduced AR and VEGFA protein levels, which was consistent with the results obtained from the cells transfected with siRNA for AR (Fig. 6A and B). To examine the effects of MDV3100 on HUVEC recruitment, CM from shNf1-SW10 cells and shNf1 fibroblasts was used to attract HUVECs. The results indicated a weakened HUVEC migration in the aforementioned groups (Fig. 6C). In addition, diminished tube formation was noted in the presence of CM from cells with MDV3100 treatment. The activation of the AR signaling following DHT treatment promoted HUVEC recruitment and tube formation, which was consistent with the results noted in Fig. 3.

The results shown in Fig. 6 demonstrated that the inhibition of AR signaling suppressed HUVEC recruitment and impaired tube formation of these cells, which further suggested that the inhibition of AR signaling could partially disrupt the angiogenesis of neurofibroma.

\section{Discussion}

Cutaneous neurofibromas are usually associated with morbidity and exhibit resistance to conventional chemotherapy. To date, several promising treatments have failed to show therapeutic efficacy in clinical trails (19-22), which highlights the importance of identifying molecular mechanisms and novel targets for these neoplasms. In the present study, we identified several potential
AR binding sites in the promoter of VEGFA and demonstrated that activated AR significantly enhanced VEGFA transcription. The aforementioned findings were similar with the regulation of the VEGFA transcription by the AR noted in bladder cancer (23). Moreover, an elevated AR expression and MVD were found in human cNF samples, whereas AR protein levels were associated with MVD (Fig. 1), which further confirmed the regulatory role of $\mathrm{AR}$ in regulating VEGFA expression in $\mathrm{CNF}$.

Although the hyperproliferation of neural crest tumors are considered hallmark features of NF1, specific disorders that are often found in affected individuals include hypertension, an increased probability of vascular diseases and congenital heart disease that are not directly related to the neural system (24-26). Neurofibromin is also expressed in endothelial and smooth muscle cells (27), suggesting that an altered neurofibromin function in these cells may be attributed to vasculopathy in patients with NF1. cNF is widely accepted as a vascularized type of solid tumor with complex $\mathrm{Nf}^{+/}$cells comprising Schwann cells, fibroblasts, endothelial and inflammatory cells. The role of endothelial cells in $\mathrm{cNF}$ development has not been well defined. The results of this study demonstrated an increased HUVEC proliferation and recruitment accompanied by an enhanced tube formation ability upon interaction of these cells with neurofibroma cells. This disposition of HUVECs led to the accelerated angiogenesis noted in neurofibroma.

The angiogenic effects of the endothelial cells are mainly driven by VEGF (28) and preliminary studies have demonstrated 

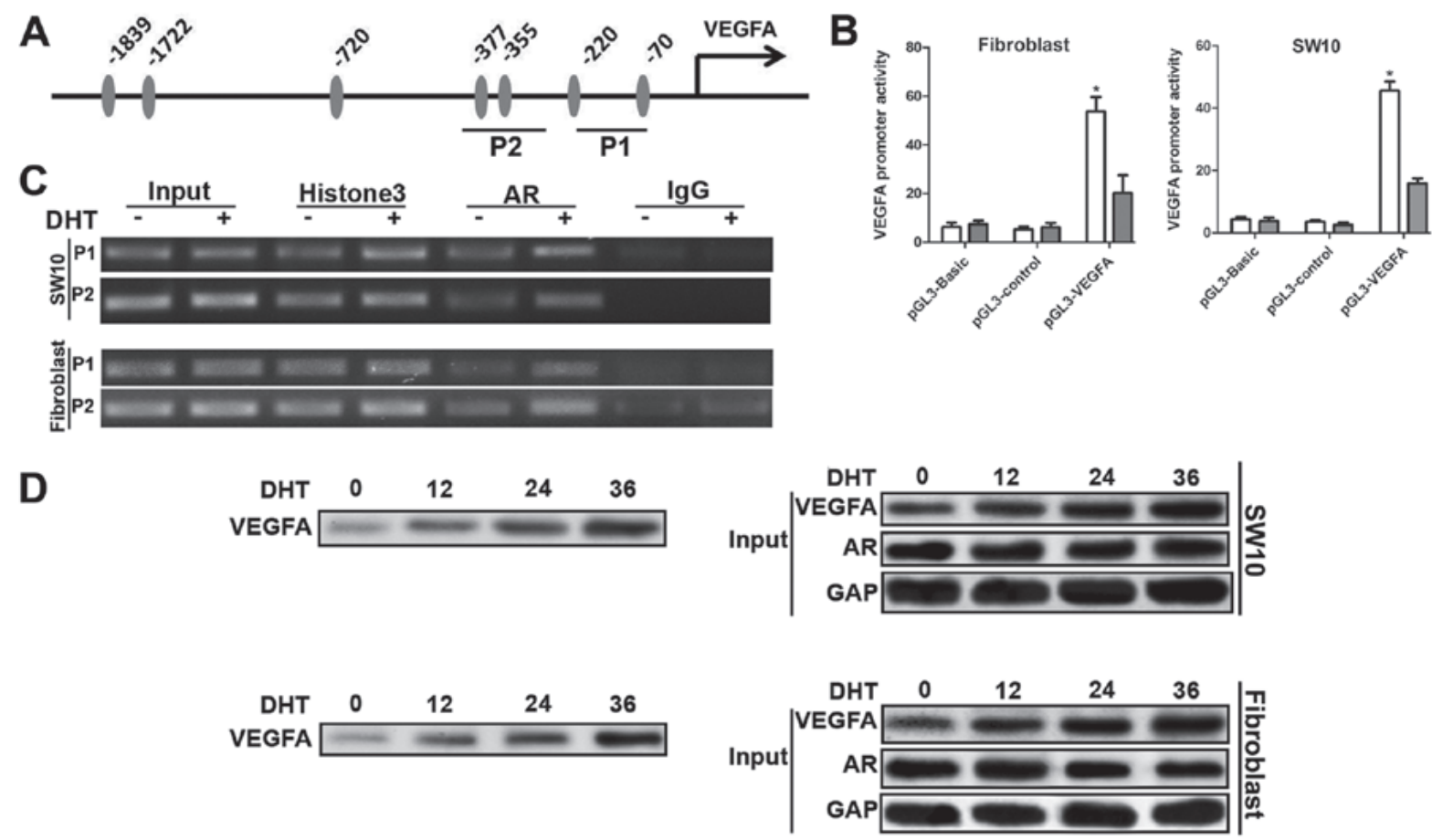

Figure 5. Androgen receptor (AR) regulates VEGFA transcriptional activity by direct binding to its promoter. (A) Schematic illustration of the putative AR binding sites. The primer design for the ChIP assay and the oligo pulldown assay for the human VEGFA promoter are shown. (B) pGL3-control or pGL3-VEGFA (harboring the fragment of the VEGFA promoter) plasmids were used to treat shNf1-SW10 cells and shNf1 fibroblasts. The cells were also examined in the absence of plasmids (control). The cells were treated with DHT or saline for $48 \mathrm{~h}$ prior to the initiation of the dual luciferase activity assay. (C) ChIP assay of AR binding to the VEGFA promoter. The DNA was prepared and an antibody against AR was used to pulldown the protein-DNA complex. The primers of specific sets were used to analyse the immuno-precipitated DNA. (D) In $5 \mathrm{ng} / \mathrm{ml}$ of DHT-treated cells, oligonucleotide pull-down assays and western blot analhysis were performed to detect AR binding to the VEGFA promoter. " $\mathrm{P}<0.05$.
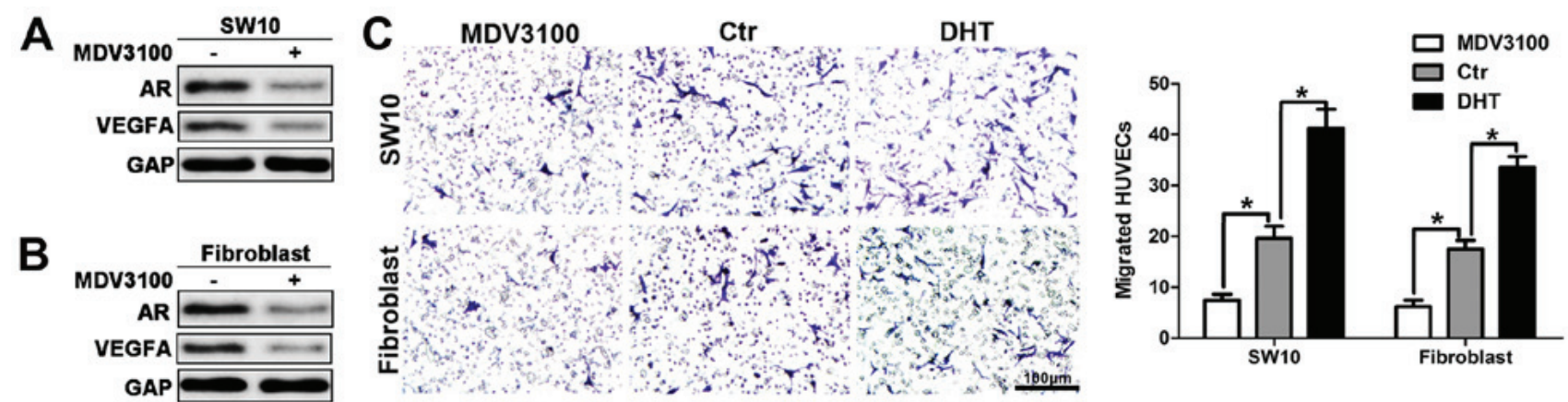

D
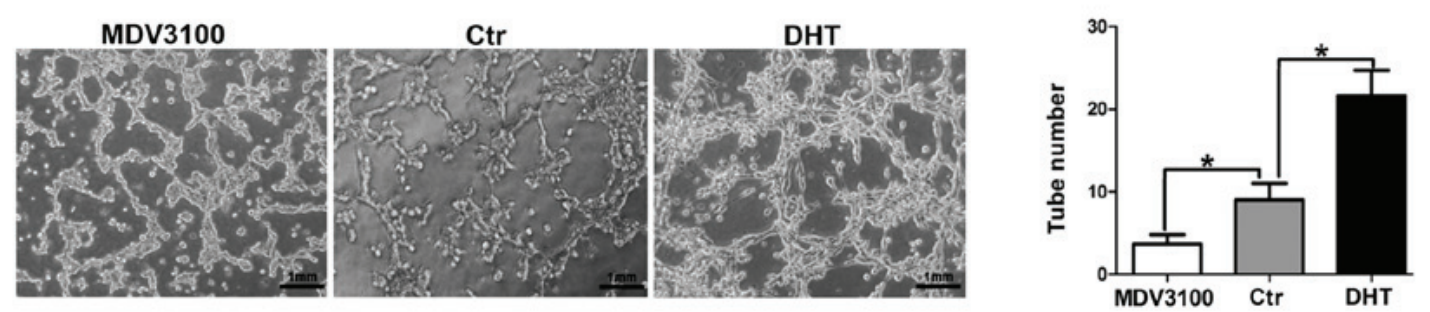

Figure 6. Androgen receptor (AR) is required for angiogenesis. (A and B) AR and VEGFA protein levels in the MDV3100-treated cells were detected by western blot analysis. (C) shNf1-clones were seeded to the lower chamber of the Transwell system in the presence of DHT and/or MDV3100 and the migratory activity of HUVECs was evaluated (x200 magnification) (left panel, representative pictures; right panel, quantitative data). (D) The AR inhibitor MDV3100 reduced tube formation, while DHT promoted tube formation in HUVECs. Representative images of tubes are presented and the tube number in each well was counted (right panel). ${ }^{*} \mathrm{P}<0.05$.

an altered angiogenesis, which is associated with the signaling of $\mathrm{Nf}^{+/-}$. In addition, Schwann cells express and secrete various types of ligands (29-33), which are capable of regulating multiple cell functions in the neurofibroma microenvironment.
The results demonstrated that the knockdown of the $N f 1$ gene increased VEGFA secretion in Schwann cells and fibroblasts, which were considered the principal cells encountered in neurofibroma (pathognomonic tumor of NF1). In addition, 
Nf1-k/o HUVECs exhibited optimal recruitment and an angiogenic phenotype. Therefore VEGFR in HUVECs may participate in this process, which is possibly associated with tumor progression. This finding is consistent with the findings of previous studies (34-37) reporting that neurofibroma-associated growth factors (e.g., PDGF and VEGF) can alter the function of endothelial cells with dysfunctional neurofibromin, which is considered a critical step in angiogenesis.

It is widely accepted that the transformation of the endothelial cells to the angiogenic phenotype plays a key role for the increase in tumor size $(38,39)$. Angiogenesis may be critical for $\mathrm{cNF}$ enlargement, since $\mathrm{cNF}$ can be increased to a substantial tumor mass $(\mathrm{kg})$. Schwann cells with neurofibromin loss have been shown to promote angiogenesis $(40,41)$ and increase VEGF secretion. Although an increased vascular density is noted in malignant peripheral nerve sheath tumor (MPNST), the mechanism of the angiogenic switch requires further clarification (10). The association of steroid hormones with $\mathrm{cNF}$ is due to the role of this tumor at puberty (43). An increase in numbers and size can be observed during puberty and pregnancy (42), which suggests that the elevated steroid hormones during puberty may contribute to the 'aggressiveness' of cNF progression. The present study indicated an amplified MVD and increased AR expression in human neurofibroma tissues. Moreover, the data indicated that activated AR signaling can enhance tube formation in vitro and in vivo. Our results suggested that activated AR signaling promoted vascular formation that in turn contributed to neurofibroma growth. These findings are in concordance with those of previous studies (43-45).

AR expression is ubiquitously found in various types of cells $(46,47)$. Upon the binding of an androgen to the AR, the receptor is activated and translocates to the nucleus. The activated receptor binds to the specific DNA sequences in the promoter of target genes, and modulates gene transcription (48). In the present study, we detected the expression levels of genes that are implicated in angiogenesis and found that AR promoted angiogenesis by regulating VEGF expression. We further explored the molecular mechanisms of AR with regard to the upregulation of VEGFA by monitoring its direct binding to the corresponding promoter region. The inhibition of steroid hormones is often used as a clinical therapeutic strategy. Enzalutamide (MDV3100) is an AR inhibitor approved by FDA for prostate cancer treatment. The results of the present study suggested that MDV3100 was capable of diminishing HUVEC infiltration and suppressing tube formation, which indicated the therapeutic potential of androgen-AR inhibition in neurofibroma (Fig. 6).

In conclusion, the present study indicated that the aberrant activation of androgen-AR signaling may increase VEGFA expression and vascularization of neurofibroma in male patients with cNF. Increased VEGFR contributes to HUVEC recruitment and consequently in enhanced angiogenesis and neurofibroma progression. Targeting the newly identified pathway of angiogenesis may open a novel avenue for the effective treatment of $\mathrm{cNF}$.

\section{Acknowledgements}

Not applicable.

\section{Funding}

The present study was supported by the general project of major research plan for social development of the Shaanxi province (grand no. 2018SF-250 to JJ).

\section{Availability of data and materials}

All data generated or analyzed during the present study are included in this published article.

\section{Authors' contributions}

MS designed the experiments, conducted the data analyses and wrote the manuscript. HZ and WL performed the clinical sample preparation and validated CD31 and AR expression in neurofibroma tissues. HZ and JJ performed the cellular experiments and HD performed the in vivo assays. All authors participated in the discussion and revision of the manuscript. All authors have read and approved the final version of the manuscript.

\section{Ethics approval and consent to participate}

All procedures performed involving human participants were in accordance with the ethical standards of the Institutional Review Board of the First Affiliated Hospital of Xi'an Jiaotong University. The study adhered to the guidelines of the 1964 Helsinki declaration and its later amendments or comparable ethical standards. The animal experiments were approved by the Institutional Review Board of the First Affiliated Hospital of Xi'an Jiaotong University.

\section{Patient consent for publication}

No applicable.

\section{Competing interests}

The authors declare that they have no competing interests.

\section{References}

1. Huson SM, Compston DA, Clark P and Harper PS: A genetic study of von Recklinghausen neurofibromatosis in south east Wales. I. Prevalence, fitness, mutation rate, and effect of parental transmission on severity. J Med Genet 26: 704-711, 1989.

2. Gutmann DH, Ferner RE, Listernick RH, Korf BR, Wolters PL and Johnson KJ: Neurofibromatosis type 1. Nat Rev Dis Primers 3: 17004, 2017.

3. Dugoff L and Sujansky E: Neurofibromatosis type 1 and pregnancy. Am J Med Genet 66: 7-10, 1996.

4. McLaughlin ME and Jacks T: Neurofibromatosis type 1. Methods Mol Biol 222: 223-237, 2003.

5. Posma E, Aalbers R, Kurniawan YS, van Essen AJ, Peeters PM and van Loon AJ: Neurofibromatosis type I and pregnancy: A fatal attraction? Development of malignant schwannoma during pregnancy in a patient with neurofibromatosis type I. BJOG 110: $530-532,2003$.

6. Jung-Testas I, Schumacher M, Bugnard H and Baulieu EE: Stimulation of rat Schwann cell proliferation by estradiol: Synergism between the estrogen and cAMP. Brain Res Dev Brain Res 72: 282-290, 1993.

7. Jung-Testas I, Schumacher M, Robel $\mathrm{P}$ and Baulieu EE: Demonstration of progesterone receptors in rat Schwann cells. J Steroid Biochem Mol Biol 58: 77-82, 1996. 
8. Pennanen P, Peltonen S, Kallionpää RA and Peltonen J: The effect of estradiol, testosterone, and human chorionic gonadotropin on the proliferation of Schwann cells with $\mathrm{NF}^{+/-}$or $\mathrm{NF}^{-/}$genotype derived from human cutaneous neurofibromas. Mol Cell Biochem 444: 27-33, 2018.

9. Gao W, Bohl CE and Dalton JT: Chemistry and structural biology of androgen receptor. Chem Rev 105: 3352-3370, 2005.

10. Gesundheit B, Parkin P, Greenberg M, Baruchel S, Senger C, Kapelushnik J, Smith C and Klement GL: The role of angiogenesis in the transformation of plexiform neurofibroma into malignant peripheral nerve sheath tumors in children with neurofibromatosis type 1. J Pediatr Hematol Oncol 32: 548-553, 2010.

11. Staser K, Yang FC and Clapp DW: Pathogenesis of plexiform neurofibroma: Tumor-stromal/hematopoietic interactions in tumor progression. Annu Rev Pathol 7: 469-495, 2012.

12. Staser K, Yang FC and Clapp DW: Mast cells and the neurofibroma microenvironment. Blood 116: 157-164, 2010.

13. Needle MN, Cnaan A, Dattilo J, Chatten J, Phillips PC, Shochat S Sutton LN, Vaughan SN, Zackai EH, Zhao H, et al: Prognostic signs in the surgical management of plexiform neurofibroma: The Children's Hospital of Philadelphia experience, 1974-1994. J Pediatr 131: 678-682, 1997.

14. Folkman J: Tumor angiogenesis: Therapeutic implications N Engl J Med 285: 1182-1186, 1971

15. Folkman J: New perspectives in clinical oncology from angiogenesis research. Eur J Cancer 32A: 2534-2539, 1996.

16. Folkman J: Fighting cancer by attacking its blood supply. Sci Am 275: 150-154, 1996

17. Hanahan D and Folkman J: Patterns and emerging mechanisms of the angiogenic switch during tumorigenesis. Cell 86: 353-364, 1996.

18. Fukumura D, Xavier R, Sugiura T, Chen Y, Park EC, Lu N, Selig M, Nielsen G, Taksir T, Jain RK, et al: Tumor induction of VEGF promoter activity in stromal cells. Cell 94: 715-725, 1998

19. Babovic-Vuksanovic D, Ballman K, Michels V, McGrann P, Lindor N, King B, Camp J, Micic V, Babovic N, Carrero X, et al: Phase II trial of pirfenidone in adults with neurofibromatosis type 1. Neurology 67: 1860-1862, 2006.

20. Gupta A, Cohen BH, Ruggieri P, Packer RJ and Phillips PC Phase I study of thalidomide for the treatment of plexiform neurofibroma in neurofibromatosis 1. Neurology 60: 130-132, 2003

21. Widemann BC, Dombi E, Gillespie A, Wolters PL, Belasco J, Goldman S, Korf BR, Solomon J, Martin S, Salzer W, et al: Phase 2 randomized, flexible crossover, double-blinded, placebo-controlled trial of the farnesyltransferase inhibitor tipifarnib in children and young adults with neurofibromatosis type 1 and progressive plexiform neurofibromas. Neuro Oncol 16: 707-718, 2014.

22. Widemann BC, Salzer WL, Arceci RJ, Blaney SM, Fox E, End D Gillespie A, Whitcomb P, Palumbo JS, Pitney A, et al: Phase I trial and pharmacokinetic study of the farnesyltransferase inhibitor tipifarnib in children with refractory solid tumors or neurofibromatosis type I and plexiform neurofibromas. J Clin Oncol 24: 507-516, 2006

23. Gao Y, Wu K, Chen Y, Zhou J, Du C, Shi Q, Xu S, Jia J, Tang X, $\mathrm{Li} \mathrm{F}$, et al: Beyond proliferation: KLF5 promotes angiogenesis of bladder cancer through directly regulating VEGFA transcription. Oncotarget 6: 43791-43805, 2015.

24. Hamilton SJ, Allard MF and Friedman JM: Cardiac findings in an individual with neurofibromatosis 1 and sudden death. Am J Med Genet 100: 95-99, 2001.

25. Rasmussen SA, Yang Q and Friedman JM: Mortality in neurofibromatosis 1: An analysis using U.S. death certificates. Am J Hum Genet 68: 1110-1118, 2001

26. Friedman JM, Arbiser J, Epstein JA, Gutmann DH, Huot SJ, Lin AE, McManus B and Korf BR: Cardiovascular disease in neurofibromatosis 1: Report of the NF1 Cardiovascular Task Force. Genet Med 4: 105-111, 2002.

27. Hamilton SJ and Friedman JM: Insights into the pathogenesis of neurofibromatosis 1 vasculopathy. Clin Genet 58: 341-344, 2000.

28. Ferrara N: VEGF and the quest for tumour angiogenesis factors Nat Rev Cancer 2: 795-803, 2002.

29. Mashour GA, Ratner N, Khan GA, Wang HL, Martuza RL and Kurtz A: The angiogenic factor midkine is aberrantly expressed in NF1-deficient Schwann cells and is a mitogen for neurofibroma-derived cells. Oncogene 20: 97-105, 2001.
30. Hirota S, Nomura S, Asada H, Ito A, Morii E and Kitamura Y: Possible involvement of c-kit receptor and its ligand in increase of mast cells in neurofibroma tissues. Arch Pathol Lab Med 117: 996-999, 1993

31. Mashour GA, Driever PH, Hartmann M, Drissel SN, Zhang T, Scharf B, Felderhoff-Müser U, Sakuma S, Friedrich RE, Martuza RL, et al: Circulating growth factor levels are associated with tumorigenesis in neurofibromatosis type 1. Clin Cancer Res 10: 5677-5683, 2004

32. Ryan JJ, Klein KA, Neuberger TJ, Leftwich JA, Westin EH, Kauma S, Fletcher JA, DeVries GH and Huff TF: Role for the stem cell factor/KIT complex in Schwann cell neoplasia and mast cell proliferation associated with neurofibromatosis. J Neurosci Res 37: 415-432, 1994

33. Yang FC, Ingram DA, Chen $\mathrm{S}$, Hingtgen $\mathrm{CM}$, Ratner $\mathrm{N}$, Monk KR, Clegg T, White H, Mead L, Wenning MJ, et al: Neurofibromin-deficient Schwann cells secrete a potent migratory stimulus for $\mathrm{Nf}^{+/-}$mast cells. J Clin Invest 112: 1851-1861, 2003.

34. Munchhof AM, Li F, White HA, Mead LE, Krier TR, Fenoglio A, Li X, Yuan J, Yang FC and Ingram DA: Neurofibroma-associated growth factors activate a distinct signaling network to alter the function of neurofibromin-deficient endothelial cells. Hum Mol Genet 15: 1858-1869, 2006.

35. Kawachi Y, Xu X, Ichikawa E, Imakado S and Otsuka F: Expression of angiogenic factors in neurofibromas. Exp Dermatol 12: 412-417, 2003.

36. Kotsuji-Maruyama T, Imakado S, Kawachi $\mathrm{Y}$ and Otsuka F: PDGF-BB induces MAP kinase phosphorylation and VEGF expression in neurofibroma-derived cultured cells from patients with neurofibromatosis 1. J Dermatol 29: 713-717, 2002.

37. Kawachi Y, Maruyama H, Ishitsuka Y, Fujisawa Y, Furuta J, Nakamura Y, Ichikawa E, Furumura M and Otsuka F: NF1 gene silencing induces upregulation of vascular endothelial growth factor expression in both Schwann and non-Schwann cells. Exp Dermatol 22: 262-265, 2013.

38. Folkman J: Angiogenesis in cancer, vascular, rheumatoid and other disease. Nat Med 1: 27-31, 1995 .

39. Folkman J: Seminars in Medicine of the Beth Israel Hospital, Boston. Clinical applications of research on angiogenesis. NEngl J Med 333: 1757-1763, 1995.

40. Sheela S, Riccardi VM and Ratner N: Angiogenic and invasive properties of neurofibroma Schwann cells. J Cell Biol 111: 645-653, 1990

41. Kim HA, Ling B and Ratner N: Nf1-deficient mouse Schwann cells are angiogenic and invasive and can be induced to hyperproliferate: Reversion of some phenotypes by an inhibitor of farnesyl protein transferase. Mol Cell Biol 17: 862-872, 1997.

42. McLaughlin ME and Jacks T: Progesterone receptor expression in neurofibromas. Cancer Res 63: 752-755, 2003.

43. Sieveking DP, Lim P, Chow RW, Dunn LL, Bao S, McGrath KC, Heather AK, Handelsman DJ, Celermajer DS and Ng MK: A sex-specific role for androgens in angiogenesis. J Exp Med 207: 345-352, 2010.

44. Wu M, Wallace MR and Muir D: Nf1 haploinsufficiency augments angiogenesis. Oncogene 25: 2297-2303, 2006.

45. Harigai R, Sakai S, Nobusue H, Hirose C, Sampetrean O, Minami N, Hata Y, Kasama T, Hirose T, Takenouchi T, et al: Tranilast inhibits the expression of genes related to epithelial-mesenchymal transition and angiogenesis in neurofibromin-deficient cells. Sci Rep 8: 6069, 2018

46. Lin AL, McGill HC Jr and Shain SA: Hormone receptors of the baboon cardiovascular system. Biochemical characterization of myocardial cytoplasmic androgen receptors. Circ Res 49: 1010-1016, 1981

47. Horwitz KB and Horwitz LD: Canine vascular tissues are targets for androgens, estrogens, progestins, and glucocorticoids. J Clin Invest 69: 750-758, 1982 .

48. Mangelsdorf DJ, Thummel C, Beato M, Herrlich P, Schütz G, Umesono K, Blumberg B, Kastner P, Mark M, Chambon P, et al: The nuclear receptor superfamily: The second decade. Cell 83 : 835-839, 1995. 